\title{
Relation Between Firing Conditions Grain Boundary Structure and Magnetic Properties in Polycrystalline MnZn-Ferrites
}

\author{
V.T. ZASPALIS, ${ }^{*}$ V. TSAKALOUDI \& E. PAPAZOGLOU \\ Center for Research and Development-Hellas, Chemical Process Engineering Research Institute, Laboratory of Inorganic Materials, \\ P.O. Box 361, 57001 Thessaloniki, Greece
}

Submitted October 16, 2003; Revised November 11, 2003; Accepted November 14, 2003

\begin{abstract}
The influence of the firing conditions on the nanoscale structure of the grain boundaries and on the magnetic properties of polycrystalline MnZn-ferrites is investigated, on specimens of nearly identical microstructures. High oxygen partial pressures favor accumulation of impurity ions at the triple points. Under appropriate oxygen pressures homogeneous accumulation of impurities along the grain boundaries may occur, revealing therefore chemically pure grains and low hysteresis losses; simultaneously an increase of the grain boundary resistivity occurs that results to low eddy current losses. Managing the raw material impurity cations towards controlled grain boundary structures leads to the synthesis of MnZn-ferrites with power losses similar to those achieved when high purity raw materials are used together with externally introduced additives.
\end{abstract}

Keywords: $\mathrm{MnZn}$-ferrites, grain boundaries, magnetic properties

\section{Introduction}

The mechanism and the influence of additives on the grain boundaries and, through this, on the magnetic properties of polycrystalline manganese zinc ferrites has been extensively published in literature (e.g. 1-5). Additives accumulate along the grain boundaries during the elevated stage or during the cooling stage of the firing process. They may react towards the formation of usually low melting point and high specific resistivity non-magnetic phases [6]. The effect of such grain boundary modification is twofold: (i) the formed phases absorb stresses developed between the grains during grain growth, reducing therefore any crystallographic distortions at the grain boundaries and smoothening the transition between the grains (ii) the high specific resistivity of the phases formed by the additives are basically responsible for the high specific resistivity exhibited by the polycrystalline system, that is required by most high operation frequency applications. Calcium and silicon are the oldest and most widely used grain boundary

*To whom all correspondence should be addressed. E-mail: zaspalis@ cperi.certh.gr additive elements [7, 8]. Occasionally, niobium [1, 9], vanadium [2], bismuth [3, 4] or their combinations [2] and others, have been also studied.

However, the great majority of the studies in the scientific literature concentrate on the effect of additives on the grain boundaries $[1,8,9]$ or on the relation between grain boundary nature and magnetic properties $[10,11]$. In the patented literature the correlation between additives and magnetic properties is done directly [e.g. 12-14]. The consideration of the final firing process as a means to tailor, besides the microstructure also the nanoscale chemical and morphological characteristics of the grain boundaries and consequently the magnetic properties of polycrystalline MnZn-ferrites, to the authors knowledge, has not been included in the investigations.

In the present work the oxygen content of the atmosphere during the final firing process is investigated in relation to its influence on the chemical and morphological characteristics of the grain boundaries, and subsequently on the magnetic properties of MnZn-ferrites. As it will be shown, proper adjustment of the firing process conditions may lead to grain boundary modifications similar to those provided by the use of additives. 
The conclusions of this work provide, besides a process alternative for the partly substitution of quite often costly additives, also possibilities for the utilization of less pure, and thus less expensive, raw materials in a $\mathrm{MnZn-ferrite} \mathrm{manufacturing} \mathrm{process} \mathrm{without} \mathrm{sacrific-}$ ing on the magnetic quality of the products.

\section{Experimental}

\section{(I) Synthesis}

MnZn-ferrite polycrystalline specimens with the chemical formula $\left(\mathrm{Mn}_{0.574} \mathrm{Zn}_{0.336} \mathrm{Fe}_{0.090}^{2+}\right) \mathrm{Fe}_{2}^{3+} \mathrm{O}_{4}$, (into which it has been assumed for simplicity that all iron excess is in divalent form occupying tetrahedral positions of the cubic spinel lattice), are synthesized by conventional ceramic technology as follows:

The oxide metal precursors $\mathrm{Fe}_{2} \mathrm{O}_{3}$ (Industrial Grade) $\mathrm{Mn}_{3} \mathrm{O}_{4}$ and $\mathrm{ZnO}$ (Analytical Grade) are initially proportioned, by weighting according to $500 \mathrm{~g}$ of final material as described by the chemical formula, and subsequently mixed for about 10 minutes in the presence of $10 \mathrm{wt} \%$ water. The oxide mixture is then prefired to $850^{\circ} \mathrm{C}$ for 5 hours. The prefired powder is subjected to ball milling for 9 hours, using stainless steel milling balls and equal amounts of powder and water. No other additives are added to the powder prior to the milling or any other processing step. However, the main foreign ions present in the specimens are silicon and calcium that are found, by Induced Coupled Plasma spectroscopy (ICP), to be present in the iron and manganese oxide raw materials at concentrations of $200 \mathrm{ppm}$ and $300 \mathrm{ppm}$ respectively. The suspension received after milling is set for drying in a drying chamber at about

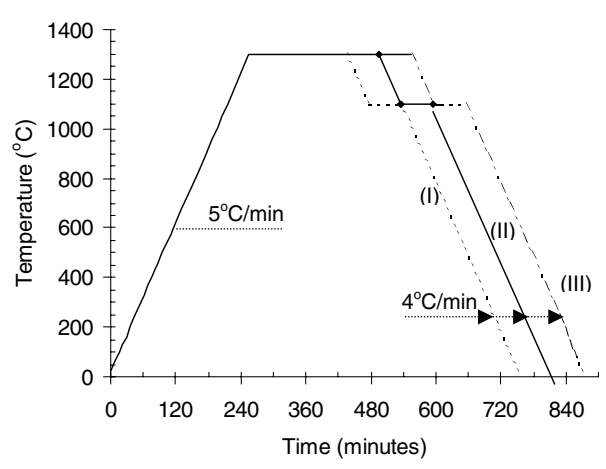

$135^{\circ} \mathrm{C}$. The so prepared milled and dried powder is granulated in a layering granulator with the addition of $10 \mathrm{wt}$. $\%$ of a binder consisting of a $2 \mathrm{wt}$. $\%$ aqueous solution of polyvinyl alcohol (Analytical Grade, molecular weight 72000). This process results to granules with an average granule size of about $500 \mu \mathrm{m}$. The granulated powder is subsequently pressed at $500 \mathrm{~kg} / \mathrm{cm}^{2}$ to toroidally shaped compacts with an external diameter of $17 \mathrm{~mm}$, an inside diameter of $11 \mathrm{~mm}$ and a height of $6 \mathrm{~mm}$. The compacted specimens are then subjected to firing at a peak temperature of $1300^{\circ} \mathrm{C}$, using specially constructed computerized kilns allowing for independently programmable temperature and oxygen partial pressure profiles. Three different firing experiments are conducted corresponding to the temperature and atmosphere profiles (I), (II) and (III) respectively, shown in Fig. 1. Each firing batch contained four specimens placed on top of each other. The two specimens placed in the middle are used for characterization. For the dilatometric experiments cylindrically shaped compacts are made with a length of $12 \mathrm{~mm}$ and a diameter of $5 \mathrm{~mm}$, after compacting under the same conditions. For the electric resistivity measurements cylindrically shaped compacts with a diameter $5 \mathrm{~mm}$ and length of $2 \mathrm{~mm}$ are used, fired simultaneously with the toroidal specimens. Gold electrodes on both edge surfaces are deposited from the gas phase by sputtering technique.

\section{(II) Material Characterization}

The green densities of the compacted specimens are measured geometrically by independent measurements of the weight and the dimensions of the specimens. The final densities after firing are measured by the

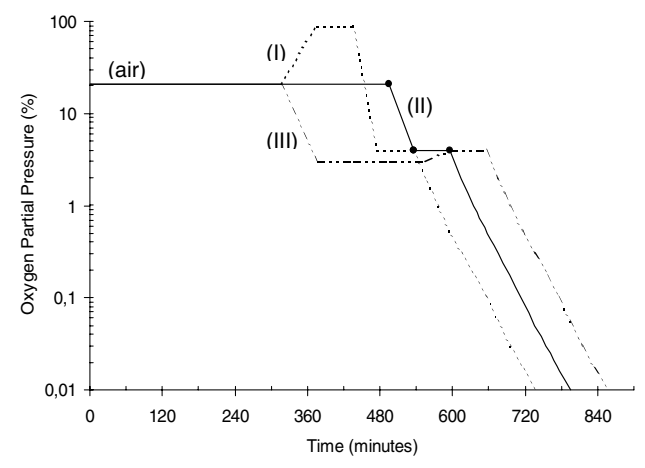

Fig. 1. Schematic presentation of the temperature and atmosphere profiles used during the firing experiments. 
Archimedes method using distilled water as the immersion fluid. The densities at intermediate sintering stage are calculated from the measured dilatometer shrinkage at firing conditions identical to those of the firing schedules. Microstructural examinations are performed with Scanning Electron Microscope (SEM) on cross sections of fired specimens after being imbedded in epoxy resin and subjected to chemical etching with aqueous acidic solution in order to visualize the grain boundaries. Quantification of the two dimensional grain sizes and grain size distributions is made with digital image analysis of ten SEM images in order to obtain representative statistics. Grain boundary nanostructural investigations are performed with a High Resolution Transmission Electron Microscope equipped with Energy Dispersive Analysis of X-rays (HRTEM-EDAX) on ion-milled samples of the fired specimens.

\section{(III) Electric and Magnetic Properties}

The specific resistivities of the fired specimens are measured under D.C. current conditions by the four pole method. The magnetic properties are measured on fired specimens wound with copper wire to form an inductor with 10-12 turns, using a computerized impedance-phase analyzer equipped with high and low frequency amplifiers, oscilloscope and temperature chamber. They are based on measurement of the alternating voltage across the winding on a specimen, the in-phase component of the current (complex permeability) and the specimen volume. The toroidal shape of the specimens allows the determination of the material properties without the influence of geometry induced demagnetization fields.

\section{Results}

In Table 1 the densities after compaction, the final sinter densities and the intermediate densities after firing for one hour at the peak temperature are shown (up to that stage there is no differentiation between the three firing schedules, Fig. 1). As shown all samples, compacted at identical conditions from the same granulate batch, have the same compaction densities and very similar firing densities. The intermediate densities are also identical since they refer to a period that is common between the three firing schedules. The D.C. current specific resistivities of the fired specimens are also shown in Table 1. An increased specific resistivity is observed for experiment 2. SEM microstructural images, of the fired specimens are shown in Fig. 2. The corresponding cumulative two dimensional grain size distributions are shown in Fig. 3. Figures 2 and 3 indicate a comparable microstructure of all specimens in terms of average grain size and grain size distribution. In Figs. 4-6 HRTEM images are shown of typical grain

Table 1. Initial, intermediate, final firing densities and d.c. specific resistivities for specimens subjected to different firing processes

\begin{tabular}{|c|c|c|c|c|c|}
\hline Exp. nr. & $\begin{array}{l}\text { Compaction } \\
\text { density }\left(\mathrm{g} \mathrm{cm}^{-3}\right)\end{array}$ & $\begin{array}{l}\text { Density after one } \\
\text { hour at } T_{\text {top }}=1300^{\circ} \mathrm{C} \\
\left(\mathrm{g} \mathrm{cm}^{-3}\right)\end{array}$ & $\begin{array}{l}\text { Final density } \\
\left(\mathrm{g} \mathrm{cm}^{-3}\right)\end{array}$ & $\begin{array}{l}\text { Firing schedule } \\
\text { (as shown in Fig. 1) }\end{array}$ & $\begin{array}{l}\text { Specific } \\
\text { D.C. resistance } \\
(\Omega \mathrm{m})\end{array}$ \\
\hline 1 & 2,95 & 4,70 & 4,84 & (I) & 5,5 \\
\hline 2 & 2,95 & 4,70 & 4,86 & (II) & 9,5 \\
\hline 3 & 2,95 & 4,70 & 4,88 & (III) & 7,0 \\
\hline
\end{tabular}
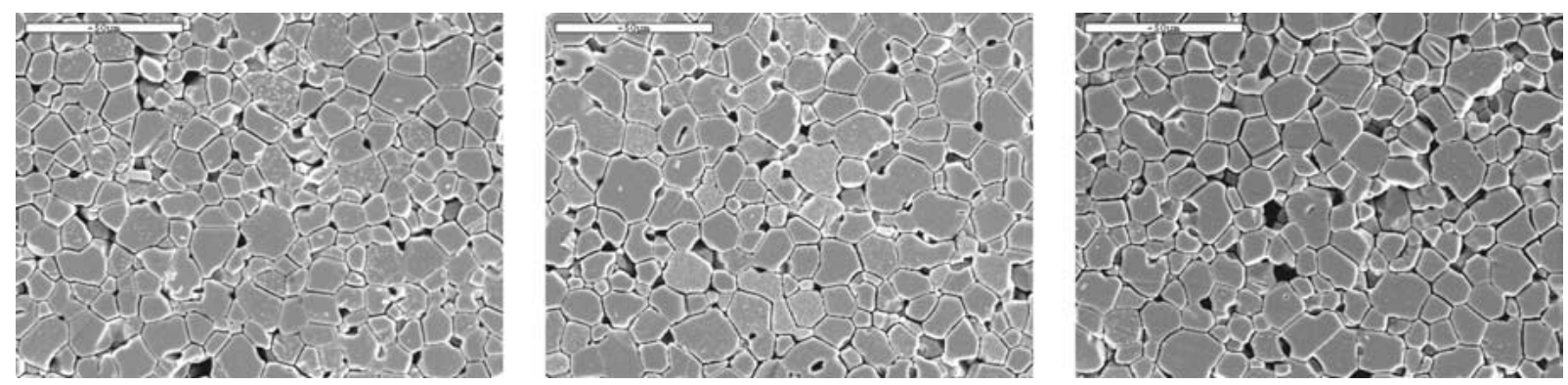

Fig. 2. Typical SEM images of microstructures of specimens of experiments 1 (left), 2 (middle) and 3 (right). 


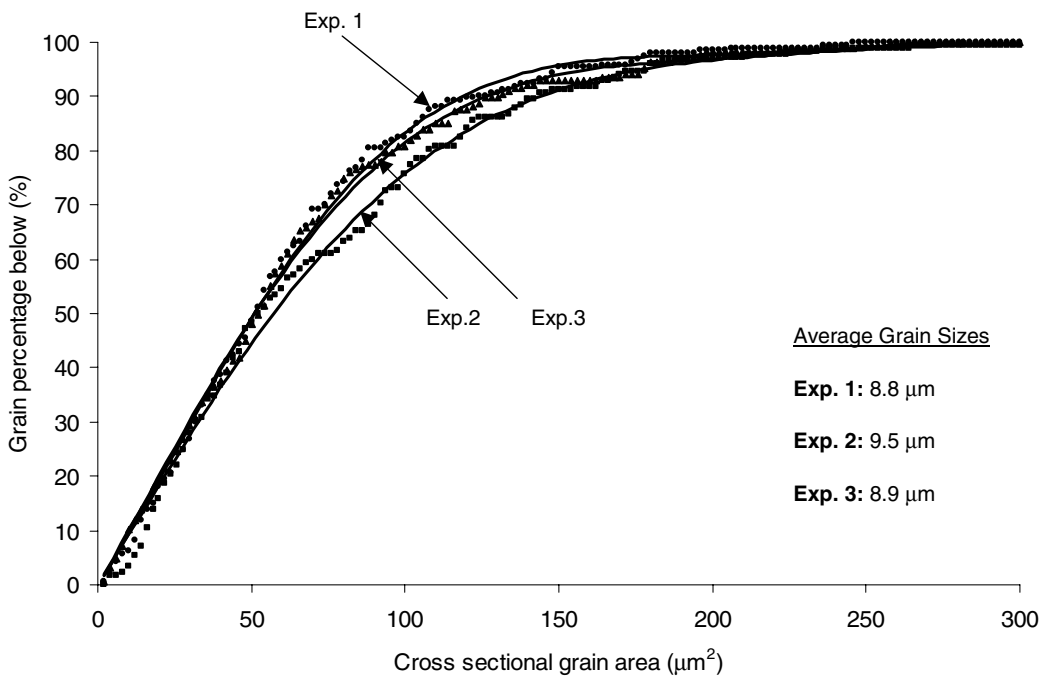

Fig. 3. Average grain sizes and cumulative cross sectional grain area distribution estimated from digital processing of SEM images.

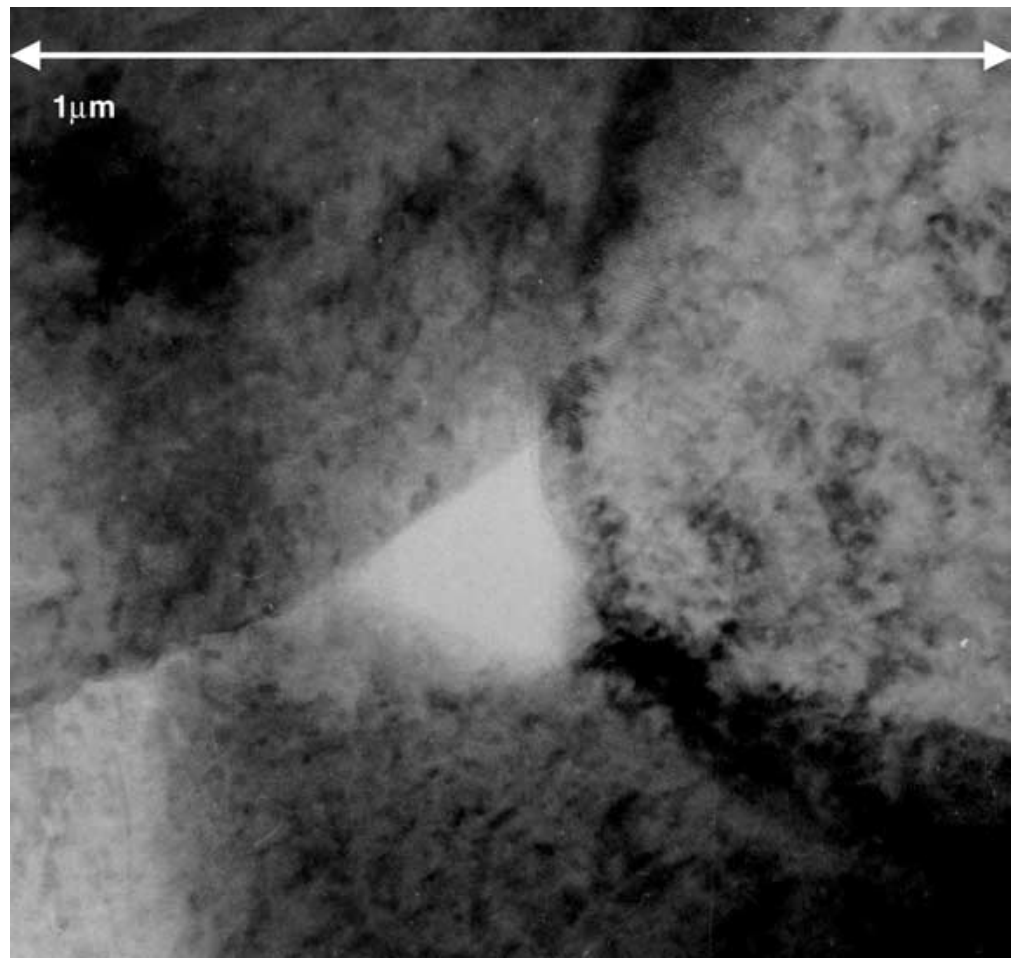

Fig. 4. Typical calcium and silicon segregation areas at the triple points of grains of specimens corresponding to experiment 1 , as obtained by HRTEM.

boundary structures that statistically dominate in specimens of experiments 1-3 (Table 1) respectively. Specimens of experiment 1 are characterized by calcium and silicon segregation at the triple points (Fig. 4). This is generally absent in specimens of experiments 2 and 3. The grain boundaries of specimens corresponding to experiment 2 are mainly characterized by the continuity of the crystallographic plane directions of the 


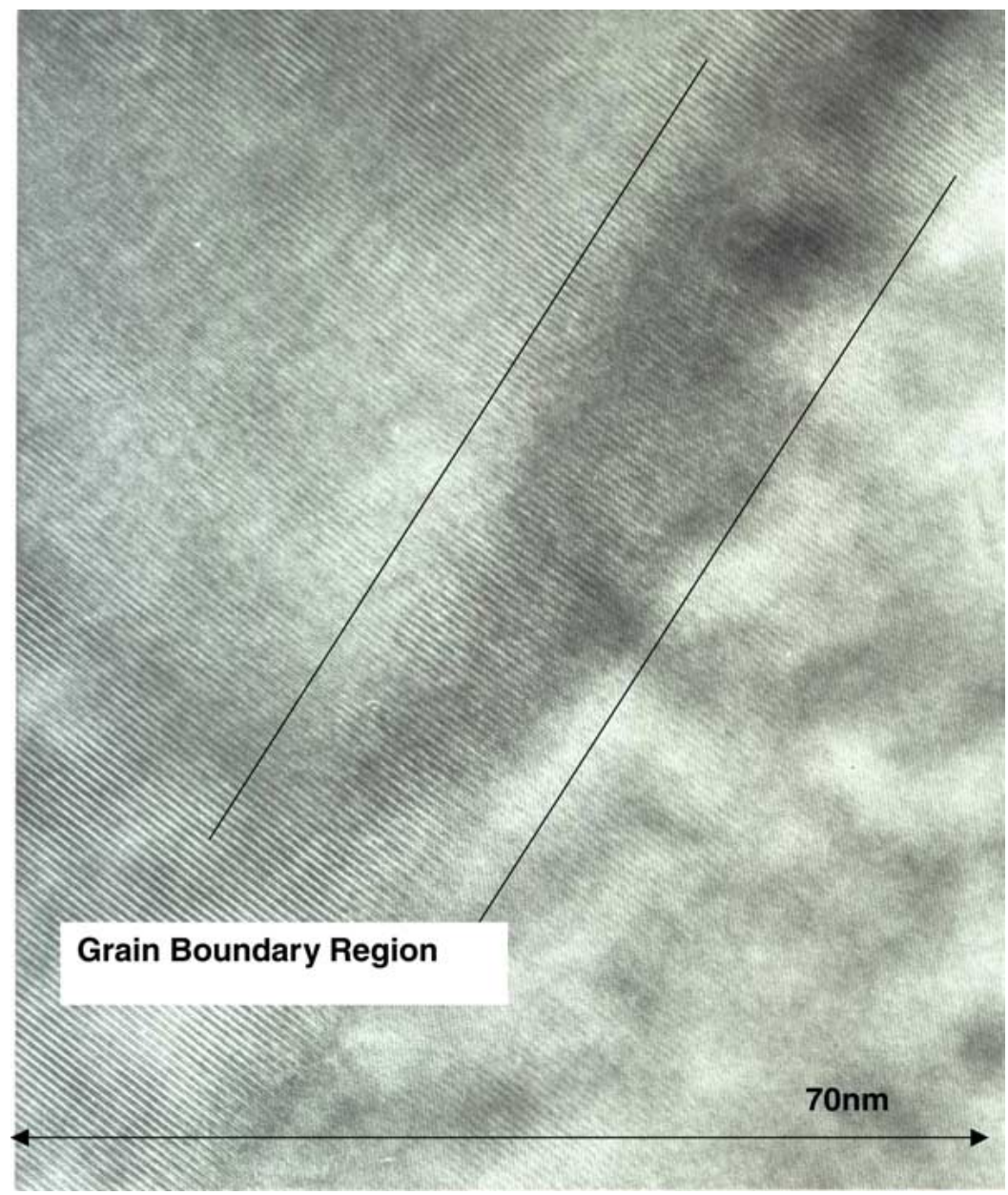

Fig. 5. Typical HRTEM microscopy image of statistically dominating grain boundary structures of specimens corresponding to experiment 2.

adjacent grains (Fig. 5). This is not observed on specimens corresponding to experiment 3 that are mainly characterized by discontinuities in the directions of the crystallographic planes (Fig. 6). The associated calcium and silicon profiles across the grain boundaries of specimens corresponding to experiments 2 and 3 are shown in Fig. 7. As can be seen sharper profiles and higher grain boundary concentrations of calcium and silicon are measured for specimens corresponding to experiment 2 when compared to those of specimens corresponding to experiment 3 .

In Fig. 8 the hysteresis loops are shown, measured at a frequency of $100 \mathrm{kHz}$, an induced induction level amplitude of $300 \mathrm{mT}$ and a temperature of $25^{\circ} \mathrm{C}$. Those frequency-field conditions are chosen since they approximate actual operation conditions in power applications for which the majority of MnZnferrites is used [15]. A narrower hysteresis loop area can be distinguished for specimens of experiment 2 and a broader for specimens of experiment 3 . The total electromagnetic power loses per frequency cycle as a function of frequency are shown in Fig. 9, measured at a temperature of $25^{\circ} \mathrm{C}$ and an induced magnetization of $100 \mathrm{mT}$. Finally, the saturation magnetization, the initial magnetic permeability and the coercivity field are listed in Table 2, measured under the conditions shown in the table. The saturation magnetization seems to be comparable for all specimens while the initial magnetic permeability is higher for the specimens corresponding to experiment 1 . The coercivity field is minimum for the specimens corresponding to experiment 2. 


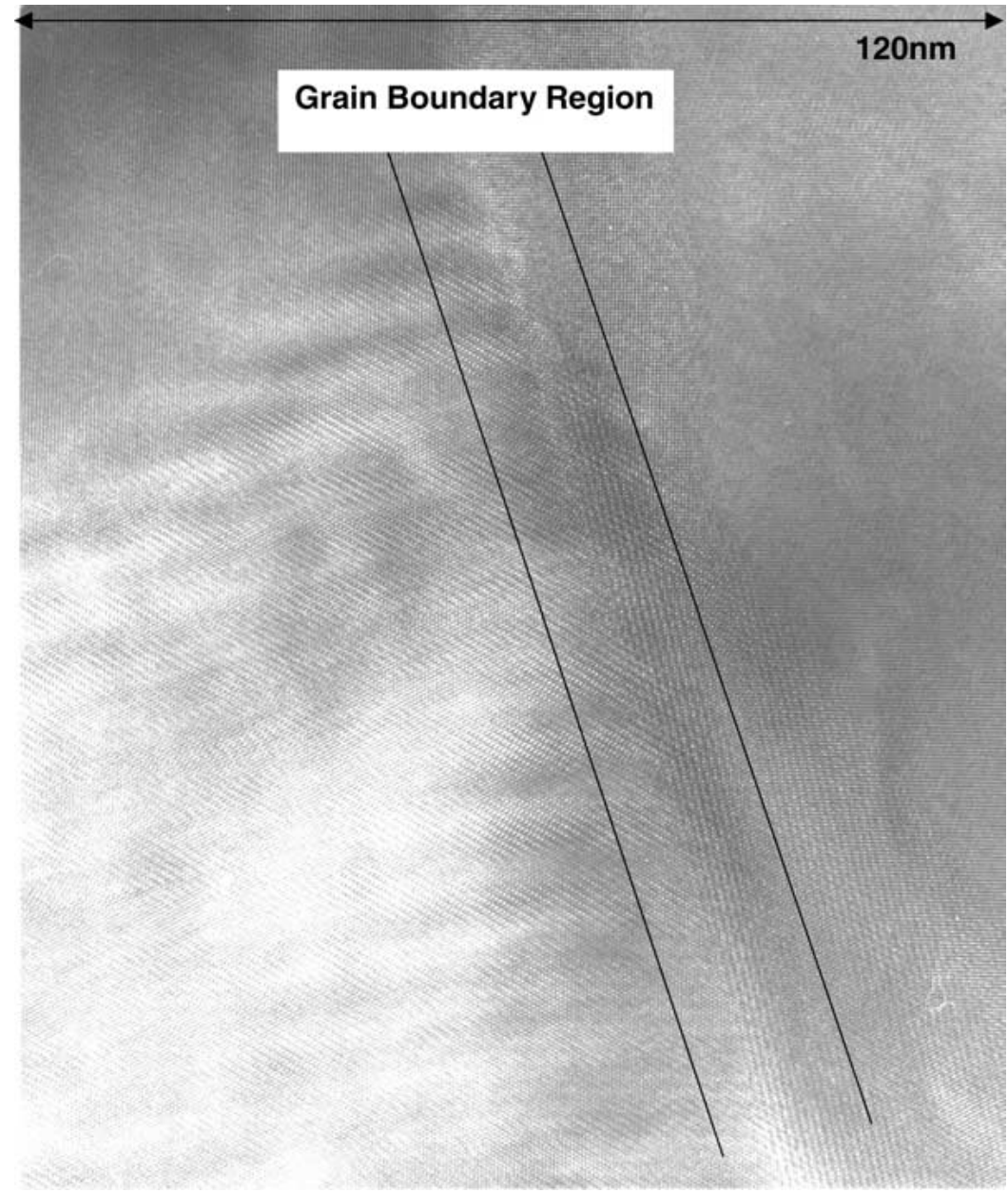

Fig. 6. Typical HRTEM microscopy image of statistically dominating grain boundary structures of specimens corresponding to experiment 3.

\section{Discussion}

By comparison of the intermediate and final density values shown in Table 1, it can be concluded that more than $95 \%$ of the densification of the specimens has taken place during that part of the firing process that is common for all specimens (e.g. up to one hour at the peak temperature of $1300^{\circ} \mathrm{C}$ ). Consequently, it is presumed that during the rest of the firing process, grain growth predominantly occurs.

The sintering mechanism of iron excess MnZnferrites is described in literature [16-18]. The materialatmosphere equilibrium relation is described, as

Table 2. Initial permeabilities, coercivity fields and saturation magnetizations for specimens subjected to different firing processes

\begin{tabular}{llll}
\hline & Initial permeability \\
& $(f<10 \mathrm{kHz}, B<0.1 \mathrm{mT})$ & Coercivity field $(\mathrm{A} / \mathrm{m})$ & Saturation magnetization $(\mathrm{mT})$ \\
Exp. nr. & $T=25^{\circ} \mathrm{C}$ & $T=25^{\circ} \mathrm{C}, f=100 \mathrm{kHz}$ & $f<10 \mathrm{kHz}, 25^{\circ} \mathrm{C}, H=250 \mathrm{~A} / \mathrm{m}$ \\
\hline 1 & 7700 & 5 & 388 \\
2 & 5330 & 6.5 & 390 \\
3 & 4600 & 10 & 391 \\
\hline
\end{tabular}




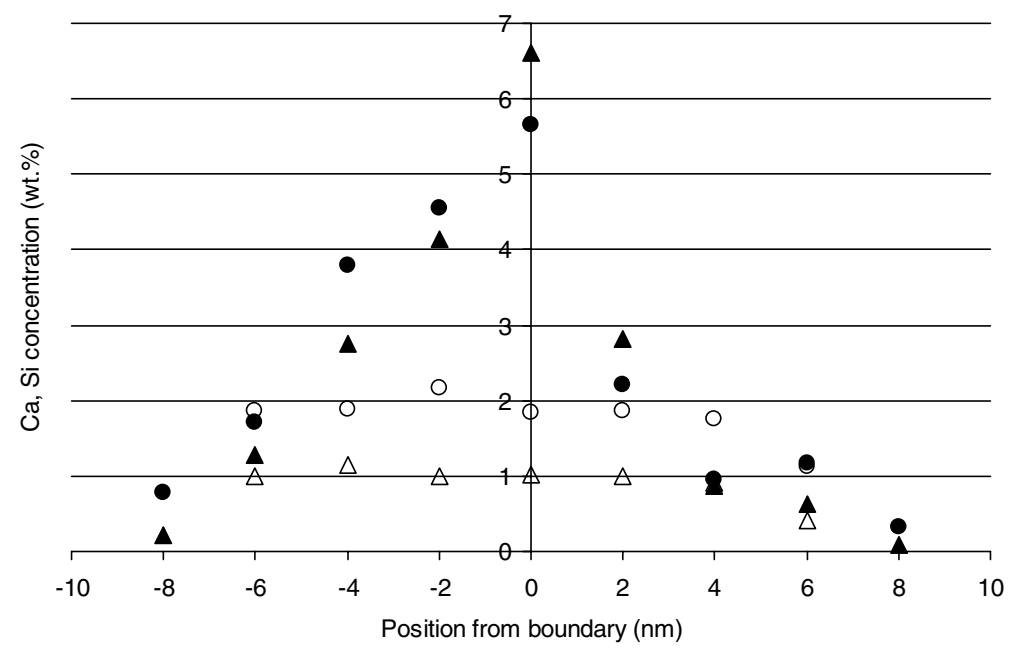

Fig. 7. Ca (triangles) and $\mathrm{Si}$ (circles) concentration distributions, as detected by HRTEM-EDAX, across grain boundaries of specimens corresponding to experiment 2 (filled symbols) and 3 (open symbols).

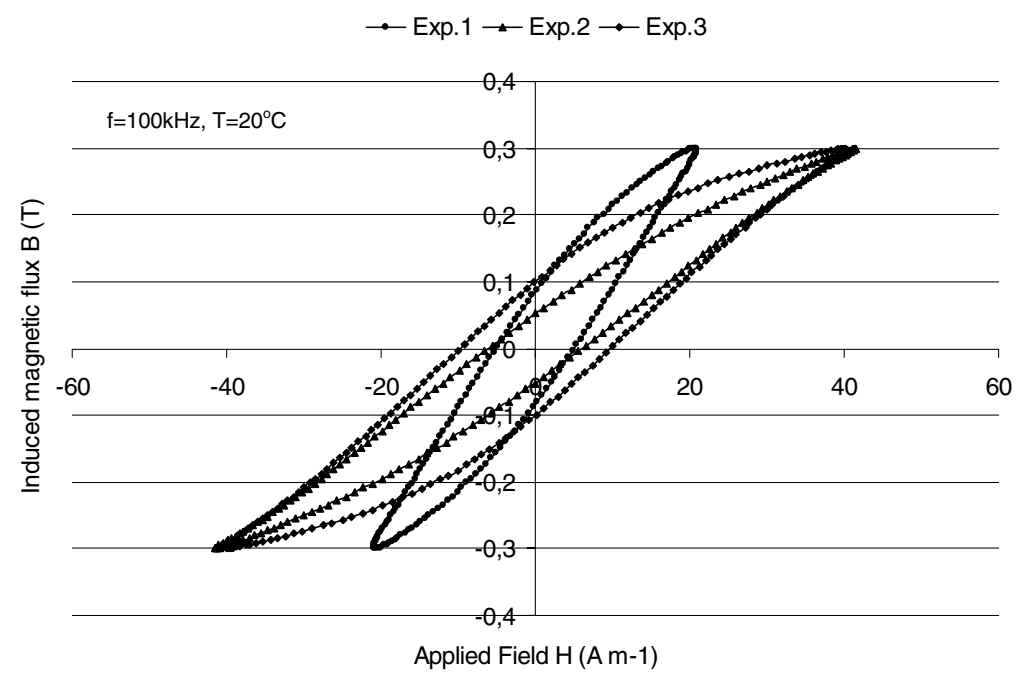

Fig. 8. Hysteresis loops under alternating current conditions of frequency $f=100 \mathrm{kHz}$ and magnetic flux amplitude of $300 \mathrm{mT}$, at $25^{\circ} \mathrm{C}$.

known, by the equation:

$$
\mathrm{Fe}^{3+}+\frac{3}{8} \mathrm{~V}_{c}+\frac{1}{2} \mathrm{O}^{2-} \leftrightarrow \mathrm{Fe}^{2+}+\frac{1}{4} \mathrm{O}_{2}
$$

According to Eq. (1) the partial pressure of oxygen in the firing atmosphere influences the concentration of cation vacancies $\left(V_{c}\right)$ in the material and consequently all processes that are related to that. Such a process is the diffusion of cations that, as known, in spinel structures and at oxygen activities similar to those employed in the experiments described here, proceeds through cation vacancies $[19,20]$. The diffusion of multivalent cations is also required for the exchange of oxygen between the material and the atmosphere, a process that causes grain boundary movement and thus grain growth.

The basic difference between firing schedules (I) to (III) (Fig. 1) is therefore the defect structure of the material at the peak temperature that is being influenced by varying the partial pressure of oxygen. The cation vacancy concentrations and consequently the diffusion 


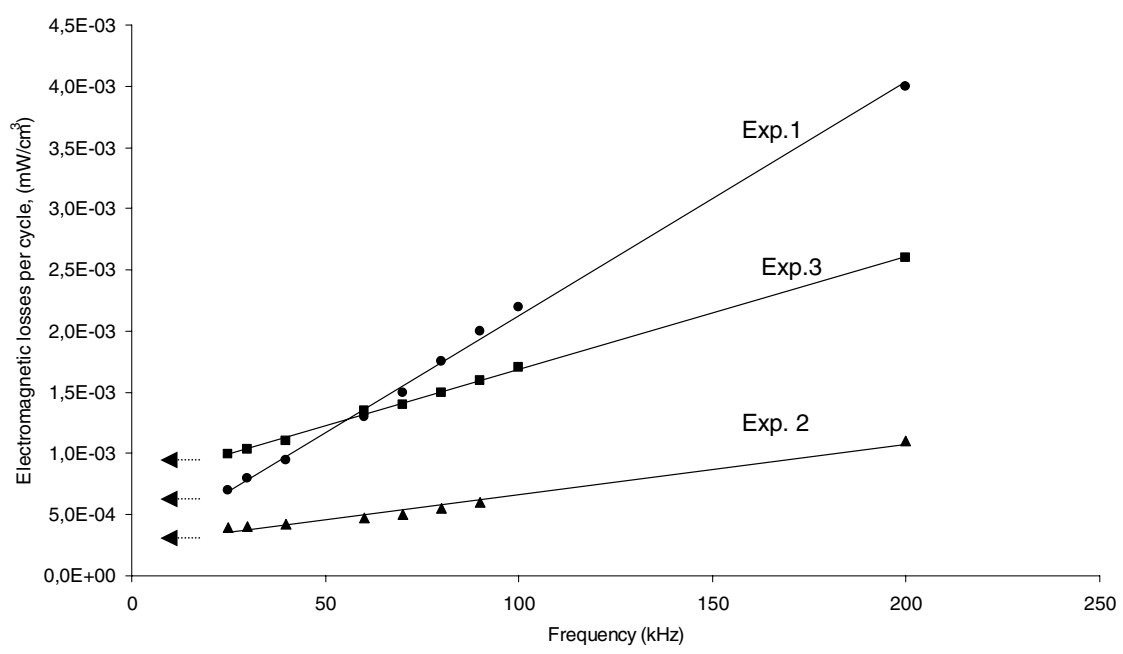

Fig. 9. Total power losses as a function of frequency at a temperature of $25^{\circ} \mathrm{C}$ and an induced magnetization of $100 \mathrm{mT}$.

rates of cations and the grain growth rates decrease as the partial pressure of oxygen decreases from firing schedule (I) to (III).

In order to cope with the different grain growth rates the dwell times at the peak temperature of $1300^{\circ} \mathrm{C}$ have been adjusted so that finally specimens with as possible identical microstructures will be obtained. Firing schedule (I) that corresponds to the highest partial pressure of oxygen has also the shorter dwell time at the peak temperature while firing schedule (III) that corresponds to the lowest partial pressure of oxygen the longer. The one-hour interval introduced to all firing schedules during cooling at $1100^{\circ} \mathrm{C}$ and always at the same partial pressure of oxygen (Fig. 1), has the purpose of ensuring the achievement of complete equilibrium between the entire bulk of the specimens and the atmosphere, corresponding to the same $\mathrm{Fe}^{2+} / \mathrm{Fe}^{3+}$ ratio. The so established oxygen content (i.e. $\mathrm{Fe}^{2+} / \mathrm{Fe}^{3+}$ ratio) at $1100^{\circ} \mathrm{C}$ is subsequently maintained down to room temperature by continuing the cooling always under equilibrium oxygen partial pressure conditions $[21,22]$.

From Figs. 2, 3 and Table 1 it is concluded that specimens from all experiments have almost identical microstructures. Final densities, average grain sizes and grain size distributions are comparable and any occurring discrepancies are considered to fall within the experimental errors.

By taking also the previous discussion into account it is concluded that specimens from all experiments (Table 1) correspond to similar chemical compositions (made from the same powder batch), to similar oxygen content (equilibritated at the same partial pressure of oxygen, Fig. 1), and to similar polycrystalline microstructures (Table 1, Figs. 2 and 3). The basic difference refers to the atmospheric conditions and consequently through Eq. (1), to the material defect structure at which firing took place at the peak temperature of $1300^{\circ} \mathrm{C}$.

In Figs. 4-6 boundary structures, typical of specimens corresponding to each experiment, are shown, as obtained by HRTEM. The nanoscale grain boundary microstructure and the behavior of the foreign to the composition elements $\mathrm{Ca}$ and $\mathrm{Si}$ differ among the various specimens and seem thus to be influenced by the firing conditions. Homogeneous grain boundary structures are mainly obtained for specimens of experiment 2 (Fig. 5). Structurally disturbed grain boundary structures with discontinuities in the crystallographic plane directions are mainly obtained for specimens of experiment 3 (Fig. 6), while foreign element ( $\mathrm{Ca}$, $\mathrm{Si}$ ) segregation at the triple points is mainly observed on specimens of experiment 1 (Fig. 4). The structural grain boundary differences between specimens of experiments 2 and 3 are also associated with differences in the calcium and silicon concentration profiles across the grain boundaries (Fig. 7). Sharper profiles with higher grain boundary concentrations are obtained for specimens of experiment 2 when compared to those of experiment 3.

The following explanation is provided: During firing at elevated temperatures, besides neck growth and pore 
elimination also diffusion of cations occurs towards occupation of their regular crystallographic lattice positions. The occupation of regular spinel lattice positions by ions like $\mathrm{Ca}^{2+}$ and $\mathrm{Si}^{4+}$ is not favored energetically. Those ions tend therefore to leave the grains and segregate in pores or along the grain boundaries. Under high grain growth rates and high cation diffusion rates, as those corresponding to experiment 1 , foreign cations are being "swept away" by the moving grain boundary towards accumulation at a thermodynamically stable position such as segregation areas at the triple points (Fig. 4). On the other extreme, under low partial pressures of oxygen where the mobility of cations is being significantly reduced, poor foreign cation accumulation at the grain boundaries is obtained (Fig. 7); it is presumed that still a significant amount remains enclosed within the bulk of the grains. At intermediate oxygen partial pressures, situations can be achieved where the great majority of the foreign cations is being homogeneously forced along the grain boundaries (Fig. 7), while leaving chemically pure bulk grains behind. Under such conditions the foreign elements act by mechanisms similar to those exhibited by dopants, rendering crystallographic plane continuity at the grain boundaries (Fig. 5). This phenomenon is absent when the firing conditions are such that do not allow the foreign cations to act as dopants (Fig. 6).

The electric and magnetic properties shown by the specimens are in qualitative agreement with the basic grain boundary characteristics. The specific resistivity results (Table 1) are in agreement with the basic grain boundary structure characteristics. As known variations in the D.C. specific resistivities of polycrystalline material systems of the same morphology and chemical composition reflect variations on the resistivities of the grain boundaries [23, 24]. The highest resistivity is measured on specimens of experiment 2 while the lowest on specimens of experiment 1 . The reason is probably the homogeneous accumulation of calcium and silicon along the grain boundaries. The degree of accumulation is probably responsible for the resistivity differences observed between specimens of experiments 2 and 3.

As shown in Table 2 all samples exhibit their secondary magnetic permeability maximum at the same temperature of $25^{\circ} \mathrm{C}$ which, for the frequency and induction conditions employed during the measurements, coincides with the temperature of the total power loss minimum. This is taken as an extra indication that all specimens contain the same $\mathrm{Fe}^{2+} / \mathrm{Fe}^{3+}$ ratio, as ex- pected on basis of the firing schedules. In Fig. 8 the hysteresis loops are shown under alternating current conditions at a frequency of $100 \mathrm{kHz}$, an induced magnetization peak flux of $300 \mathrm{mT}$ and a temperature of $25^{\circ} \mathrm{C}$. Specimens corresponding to experiment $1 \mathrm{ex}-$ hibit sharp hysteresis loops towards high induced fluxes for the same applied field. This is in agreement with the high initial magnetic permeability shown by these specimens (Table 2). It is believed that the basic reason is the disappearance of the calcium and silicon from the grain boundaries (Fig. 4) that provide the necessary grain boundary purity for achieving high permeability. Specimens corresponding to experiment 3 exhibit hysteresis loops shifted to lower induced magnetic fluxes for the same applied field, when compared to those of experiment 1 . They also exhibit larger loop areas and higher coercivity fields (Table 2). It is believed that the reason for the shifting of the hysteresis loop is related to the creation of grain boundary "phases" consisting of crystallographically distorted and possibly non-magnetic layers. Those grain boundary layers are expected to impose energetic barriers to the movement of the magnetic dipoles or magnetic domain walls, lowering therefore the magnetic permeability of the specimens. The broadening of the area of the hysteresis loop is attributed to the presence of the foreign elements calcium and silicon still in the bulk of the grains (Fig. 7), influencing therefore the crystallographic anisotropy constant of the lattice and increasing the coercivity field. The situation improves when the previous grain boundary layer is modified by the presence of calcium and silicon (Fig. 7), that, as known, due to the creation of low melting phases (together with minor amounts of always existing alkali elements like sodium or potassium), assist in maintaining better nanoscale structures (Fig. 5); this is possibly associated also with lower energetic demands, at the grain boundaries. The effect is a narrower hysteresis loop and a lower coercivity field as shown in Fig. 8.

The total power losses per frequency cycle as a function of frequency for an induced magnetization of $100 \mathrm{mT}$ and a temperature of $25^{\circ} \mathrm{C}$ are shown in Fig. 9. A linear dependency of the power losses with the frequency is obtained, in all cases, for frequencies up to $200 \mathrm{kHz}$, where resonance losses do not play a significant role. According to earlier developed empirical relations [25-28] the low frequency values may be considered to represent the frequency independent hysteresis losses; i.e. that part of the losses that occur because of the existence of hysteresis in the magnetization 
behavior of the specimens. The slope of the lines may be considered to represent the frequency linearly dependent eddy current losses; i.e. that part of the losses that occurs because of the development of ohmic eddy currents along the grains, under alternating operation conditions. This is inversely proportional to the specific resistivity of the material. There is a qualitative agreement between Figs. 8 and 9 and Table 1. The hysteresis losses are higher for the specimens of experiment 3 that show also the broader hysteresis loop (Fig. 8), while the slope is higher for the specimens of experiment 1 that show also the lower specific resistivity (Table 1). The smallest slope, i.e. the smallest eddy current loss contribution corresponds to specimens of experiment 2 that are characterized by homogeneous foreign ion accumulation along smooth grain boundary microstructures (Fig. 7). By comparing experiments 2 and 3 of Fig. 9 it can be seen that the uniform accumulation of calcium and silicon along the grain boundaries has a positive effect both on the hysteresis as well as on the eddy current losses. The removal of calcium and silicon from the bulk of the grains has a positive effect on the magnetocrystalline anisotropy and leads to reduction of the hysteresis losses; the subsequent homogeneous deposition at the grain boundaries increases the resistivity of the material, reducing therefore the eddy current losses.

\section{General Discussion}

On the mechanisms through which dopants function in order to modify the nature of the grain boundaries in polycrystalline MnZn-ferrites, has been extensively reported in literature. Calcium and Silicon are the most widely used, occasionally enriched with other elements like Niobium, Titanium, Vanadium etc. As appears from the results of this work by proper adjustment of the firing schedules, foreign elements like e.g. $\mathrm{Ca}$ and $\mathrm{Si}$ (usually already present in the raw materials as impurities), can be tuned to function at the grain boundaries in a similar way as externally added dopants. For example the specimens of experiment 2 exhibit at a frequency of $100 \mathrm{kHz}$, an induced magnetization of $100 \mathrm{mT}$ and a temperature of $25^{\circ} \mathrm{C}$, total power losses of $52 \mathrm{~mW} \mathrm{~cm}^{-3}$ that is very commendable and similar to the loss levels achieved with the usage of quite sophisticated doping mixtures $[1,2]$. Moreover the iron and manganese oxides used as raw materials in this work were of simple industrial grade. There are two interesting practical advantages of such a processing approach, with economical consequences. Part of the often costly externally added grain boundary doping elements may be eliminated as unnecessary. The manufacturing process is enabled to accept less pure and therefore cheaper raw materials.

A possible draw back is imposed by the difficulties encountered in introducing very controllable firing schedules in push through kilns, that are best suited for large-scale production. This problem does not exist in batch ovens.

In the present work, the partial pressure of oxygen is varied during the dwell time at the peak firing temperature. As pointed out during the discussion this parameter is related to the concentration of cation vacancies in the material that in turn affect the cation diffusion rate and through this the grain growth rate. It would have been of interest to study the effect of other than oxygen cation vacancy creating parameters (e.g. high valent bulk substitutions), on the grain boundary structure and the magnetic properties of the ferrites. High cation vacancy concentrations at low oxygen partial pressure could possibly lead to very interesting results. Such investigations are in progress in the laboratory.

\section{Conclusions}

The partial pressure of oxygen, or the material defect structure, during firing of MnZn-ferrites affect, at identical polycrystalline microstructures, the grain boundary structure and through this the magnetic properties of the product specimens.

At appropriate partial pressures of oxygen during firing, the impurity cations may be removed from the bulk of the grains and accumulated homogeneously along the grain boundary where they function as classical grain boundary dopants. Both hysteresis and eddy current losses are reduced.

Controllable influence of the fundamental physical processes that take place during the sintering of MnZnferrites, such as material defect structure, allows the introduction of less pure and therefore cheaper raw materials for the synthesis of MnZn-ferrites.

\section{References}

1. V.T. Zaspalis, E. Antoniadis, E. Papazoglou, V. Tsakaloudi, L. Nalbantian, and C.A. Sikalides, J. Magn. Magn. Mat., 209, 1937 (2001).

2. S.H. Chen, S.C. Chang, C.Y. Tsay, K.S. Liu, and I.N. Lin, J. Eur. Cer. Soc., 21, 1935 (2001). 
3. M. Drofenik, A. Znidarsic, and D. Makovec, J. Amer. Cer. Soc., 81, 2841 (1998).

4. P. Andrei, O. Caltun, C. Papusoi, A. Stancu, and M. Feder, J. Magn. Magn. Mat., 196/197, 362 (1999).

5. A. Goldman, Handbook of Modern Ferromagnetic Materials (Kluwer Academic Publishers, Dordrecht, 1999), p. 229.

6. E.G. Visser and M.T. Johnson, J. Magn. Magn. Mat., 101, 143 (1991).

7. A.D. Giles and F.F. Westendorp, J. de Physique, 38(1), 317 (1977).

8. J.H. Boy and G.P. Wirtz, J. Eur. Cer. Soc., 14, 227 (1994).

9. H. Inaba, T. Abe, Y. Kitano, and J. Shimomura, J. Sol. St. Chem., 121, 117 (1996).

10. M.H. Berger and J.Y. Laval, Proc. 5th Int. Conf. On Ferrites (ICF-5, New Delhi, India, 1989), p. 315.

11. J.Y. Laval, C. Cabanel, M.H. Berger, and P. Girard, J. Amer. Cer. Soc., 81(5), 1133 (1998).

12. H. Naoe, M. Tohoru, M. Teruo, and O. Katsunobu, Japanese Patent JP259448/88 (1990).

13. T. Narutani, M. Yamazaki, K. Okuno, and K. Okutani, United States Patent US5698145 (1997).

14. S. Inoue and M. Watanabe, World Patent WO9840325 (1998).
15. E.C. Snelling, Soft-Ferrites; Properties and Applications (Butterworth \& Co., London, 1988).

16. P.J.L. Reijnen, Sci. of Ceram., 4, 169 (1968).

17. A. Broese van Groenou, P.F. Bongers, and A.L. Stuyts, Mat. Sci. Eng., 3, 317 (1968).

18. A.L. Stuyts, Proc. Int. Conf. On Ferrites (ICF, Tokyo-Japan, 1970), p. 108.

19. R. Dieckmann, J. Phys. Chem. Solids, 59(4), 507 (1998).

20. J.H. Lee, M. Martin, and H.I. Yoo, J. Phys. Chem. Solids, 61, 1597 (2000).

21. R. Morineau and M. Paulus, IEEE Trans. Magn., 5, 1312 (1975).

22. M. Droefenik, A. Znidarsic, and I. Zajc, J. Appl. Phys., 82(1), 333 (1977).

23. C.R. Hendricks, V.W.R. Amarakoon, and D. Sullivan, J. Amer. Cer. Soc. Bull., 70(5), 817 (1991).

24. C.G. Koops, Phys. Rev., 83(1), 121 (1951).

25. O. Inoue, N. Matsutani, and K. Kugimiya, IEEE Trans. Magn., 29(6), 3532 (1993).

26. A. Gonchar, S. Katynkina, L. Letyuk, and I. Ryabov, J. Magn. Magn. Mat., 215/216, 224 (2000).

27. S. Yamada and E. Otsuki, J. Appl. Phys., 81(8), 4791 (1997).

28. E. Roess, Proc. Int. Conf. On Ferrites (ICF, Tokyo-Japan, 1970), p. 187 